\title{
Psychiatric comorbidity in older adults with bipolar disorder
}

\author{
Martha Sajatovic ${ }^{1 *}$, Frederic C. Blow ${ }^{2,3}$ and Rosalinda V. Ignacio ${ }^{2,3}$ \\ ${ }^{1}$ Department of Psychiatry Case Western Reserve University School of Medicine, Cleveland, OH, USA \\ ${ }^{2}$ Serious Mental Illness Treatment Research and Evaluation Center (SMITREC), Health Services Research and \\ Development, Ann Arbor VA Healthcare System, MI, USA \\ ${ }^{3}$ Department of Psychiatry, University of Michigan, Ann Arbor, MI, USA
}

\section{SUMMARY}

Introduction Comorbidity patterns and correlates among older adults with bipolar disorder (BPD) are not well understood. The aim of this analysis was to examine the prevalence of comorbid PTSD and other anxiety disorders, substance abuse and dementia in a population of 16,330 geriatric patients with BPD in a Veterans Health Administration administrative database. Methods Patients were identified from case registry files during Federal Fiscal Year 2001(FY01). Comorbidity groups were compared on selected clinical characteristics, inpatient and outpatient health resource use, and costs of care.

Results Four thousand six hundred and sixty-eight geriatric veterans with BPD were comorbid for either substance abuse, PTSD and other anxiety disorder, or dementia (28.6\% of all veterans with BPD age 60 or older). Mean age of all veterans in the four comorbidity groups was 70.0 years ( \pm SD 7.2 years). Substance abuse was seen in 1,460 (8.9\%) of elderly veterans with BPD, while PTSD was seen in 875 (5.4\%), other anxiety disorders in $1592(9.7 \%)$, and dementia in $741(4.5 \%)$ of elderly veterans. Individuals with substance abuse in this elderly bipolar population are more likely to be younger, minority, unmarried and homeless compared to elderly bipolar populations with anxiety disorders or dementia. Inpatient use was greatest among geriatric veterans with BPD and dementia compared to veterans with BPD and other comorbid conditions. Conclusion Clinical characteristics, health resource use and healthcare costs differ among geriatric patients with BPD and comorbid anxiety, substance abuse or dementia. Additional research is needed to better understand presentation of illness and modifiable factors that may influence outcomes. Copyright (C) 2006 John Wiley \& Sons, Ltd.

KEY WORDS - bipolar disorder; elderly; comorbidity; substance abuse; post-traumatic stress disorder

\section{INTRODUCTION}

Currently, in individuals over 65 years of age, prevalence rates of bipolar disorder (BPD) range from $0.1 \%$ to $0.4 \%$ (Van Gerpen et al., 1999). Although the published literature in the area of geriatric mood disorders is growing, the amount of published information is still relatively sparse, and comorbidity patterns and correlates among older adults with BPD are not well understood. In older adult populations with depression, the presence of comorbid anxiety is associated with more severe depressive symptoms, more chronic medical illness, greater functional impairment and lower quality of life (Hegel et al.,

*Correspondence to: Dr M. Sajatovic, Department of Psychiatry, University Hospitals of Cleveland, 11100 Euclid Avenue, Cleveland, Ohio 44106, USA. Tel: 216-844-2808. Fax: 440-423-1863.

E-mail: martha.sajatovic@uhhs.com
2005). There is also evidence to suggest that substance abuse outcomes may be particularly poor among the elderly (Patterson and Jeste, 1999). Among elderly individuals, dementia is associated with increased general medical costs (Langa et al., 2004). The aim of this analysis was to examine the prevalence of anxiety disorders, substance abuse and dementia in geriatric patients in a large VA data base, and to compare health resource use and costs of care by psychiatric comorbidity. We hypothesized that clinical characteristics, health resource use patterns and health care costs would differ among groups of geriatric patients with BPD and varying types of comorbidity.

\section{METHODS}

The database from which study results are derived, the National Psychosis Registry, is an ongoing registry of 
all veterans diagnosed with psychosis who have received VA services from 1988 to the present. Registry patients were identified using data obtained from the VA Patient Treatment File (PTF), census data files, and Outpatient Care Files (OPC), and were included provided that they had at least one qualifying psychosis diagnosis in Federal Fiscal Year 2001(FY01). A full report of the Psychosis Registry may be viewed over the SMITREC web site: http:// www.va.gov/annarbor-hsrd.

Diagnoses were obtained from ICD9-CM codes. Bipolar diagnoses included ICD-9 codes 296.0, 296.1, 296.4, 296.5, 296.6, 296.7, and 296.8. Substance abuse diagnoses included ICD codes 303.9, 304.0, 305.0, 304.2, 304.3, 305.6, 305.5, 304.8, 305.2, 304.1, 304.4, 304.5, 304.5, 304.9, 305.3, 305.4, 305.7, 305.8, 305.9, 303.0, 304.7, 291, 292. PTSD diagnoses included ICD code 309.81. Other anxiety diagnoses included ICD codes 300.00, 300.01, 300,02, 300.09, $300.10,300.20,300.21,300.22,300.23,300.29$, 300.3. Dementia diagnoses included ICD codes 046.1, 046.3, 290.0, 290.10, 290.11, 290.12, 290.13, $290.20,290.21,290.3,290.40,290.41,290.42$, $290.43,290.8,290.9,291.1,291.2,294.0,2941.0$, $294.11,294.8,294.9,310.0,310.1,331.0,331.1$, $331.2,331.3,331.4,331.7,331.89,331.9,332.0$, $333.0,333.4,780.9$.

Cost data are from the VA Allocation Resource Center (ARC)'s estimates. ARC cost estimates encompass direct and indirect costs, excluding capital expenses. Costs per patient (calculated among patients with any hospital use or outpatient care during the year) were evaluated in the following categories: total costs, hospital costs, outpatient costs, psychiatric costs and pharmacy costs.

Patients were characterized based on their hospital utilization during the two years following their index BPD diagnosis in FY01. For patients who had a BPD diagnosis prior to the comorbid diagnosis, the index date is when they had the first diagnosis of substance abuse, anxiety/PTSD or dementia. For patients who had a comorbid diagnosis, the index date is when they had the first diagnosis of BPD. Diagnoses were assigned during clinical visits by treating clinicians. Patients with triple diagnoses (e.g. BPD with PTSD and substance abuse) and patients with psychiatric comorbidities other than PTSD, anxiety, dementia, or substance abuse are not included in the analyses ( $N=1398,8.6 \%$ of geriatric patients with BPD).

Multinomial multivariate logistic regression models were estimated to analyze the effects of the clinical characteristics on the comorbidity groups, controlling for other covariates in the model. Statistical sig- nificance for differences between the comorbidity categories for the continuous measures presented in this study such as hospitalization, outpatient care, and costs were tested using the nonparametric KruskallWallis test.

\section{RESULTS}

\section{Clinical characteristics and comorbidity}

Table 1 demonstrates clinical characteristics of geriatric veterans with BPD and comorbid PTSD, substance abuse, other anxiety disorder or dementia in FY01. There were 4,668 individuals with BPD who were comorbid for either substance abuse, PTSD and other anxiety disorder or dementia $(28.6 \%$ of all veterans with BPD age 60 or older). Among older veterans with BPD, comorbid substance abuse was seen in 1,460 patients $(8.9 \%)$, comorbid PTSD was seen in $875(5.4 \%)$, other comorbid anxiety disorders in 1592 (9.8\%), and comorbid dementia in 741 (4.5\%). Controlling for other covariates in the multinomial logistic regression model, individuals with comorbid dementia were the oldest of the five groups, while individuals with comorbid substance abuse were the youngest (Wald $\chi^{2}=632.33, \mathrm{df}=4, p<0.0001$ ). Only approximately one-third of veterans with comorbid substance abuse were married, compared to proportion of married individuals in the order of 55$65 \%$ in the other groups (Wald $\chi^{2}=198.82, \mathrm{df}=8$, $p<0.0001)$. Homelessness was also much more common among individuals with comorbid substance abuse, with $13.2 \%$ of these individuals $(n=193)$, being homeless compared to $2 \%$ or less in the other groups (Wald $\chi^{2}=286.68, \mathrm{df}=4, p<0.0001$ ).

\section{Inpatient and outpatient care}

Table 2 demonstrates use of inpatient and outpatient care among geriatric veterans with BPD by psychiatric comorbidity. Compared to bipolar patients with comorbid PTSD, substance abuse, anxiety or dementia, bipolar patients without these comorbidities had fewer hospitalization stays (Wald $\chi^{2}=56.23, \mathrm{df}=4$, $p<0.0001$ ), and less use of outpatient visits $\left(\chi^{2}=530.68, \mathrm{df}=4, p<0.0001\right)$. Among the comorbidity groups, inpatient use was highest among individuals with comorbid dementia. With respect to outpatient services, geriatric patients with comorbid PTSD had the greatest overall use of outpatient services, while geriatric patients with comorbid dementia had the least overall use of outpatient services $\left(\chi^{2}=144.23, \mathrm{df}=3, p<0.0001\right)$. Among 
Table 1. Clinical characteristics of patients with bipolar disorder age 60 and older by psychiatric comorbidity, FY01

\begin{tabular}{|c|c|c|c|c|c|c|}
\hline \multirow[t]{2}{*}{ Clinical characteristic } & \multicolumn{6}{|c|}{ Psychiatric comorbidity group } \\
\hline & BPD only & $\begin{array}{l}\text { BPD and } \\
\text { PTSD }\end{array}$ & $\begin{array}{c}\text { BPD and } \\
\text { other anxiety }\end{array}$ & $\begin{array}{l}\text { BPD and } \\
\text { dementia }\end{array}$ & $\begin{array}{c}\text { BPD and } \\
\text { substance abuse }\end{array}$ & $\begin{array}{l}\text { Test of significance between } \\
\text { comorbidity groups (controlling } \\
\text { for other covariates) }\end{array}$ \\
\hline No. of individuals & 10,264 & 875 & 1,592 & 741 & 1,460 & \\
\hline Mean age: year $\pm S D$ & $70.4 \pm 6.9$ & $69.8 \pm 7.1$ & $70.1 \pm 6.9$ & $75.8 \pm 6.9$ & $66.8 \pm 5.8$ & $\begin{array}{l}\text { Wald } \chi^{2}=632.33 \\
\mathrm{df}=4, p<0.0001^{*}\end{array}$ \\
\hline \multicolumn{7}{|l|}{ Gender } \\
\hline Male & $9,766(95.2 \%)$ & $841(96.1 \%)$ & $1,496(94.0 \%)$ & $708(95.6 \%)$ & $1,435(98.3 \%)$ & \multirow[t]{2}{*}{$\begin{array}{l}\text { Wald } \chi^{2}=45.25 \\
\mathrm{df}=4, p=0.0001^{*}\end{array}$} \\
\hline Female & $498(4.9 \%)$ & $34(3.9 \%)$ & $96(6.0 \%)$ & $33(4.4 \%)$ & $25(1.7 \%)$ & \\
\hline \multicolumn{7}{|l|}{ Ethnicity } \\
\hline Caucasian & $7,570(73.8 \%)$ & $703(80.3 \%)$ & $1,254(78.8 \%)$ & $571(77.1 \%)$ & $1,174(80.4 \%)$ & \multirow[t]{5}{*}{$\begin{array}{l}\text { Wald } \chi^{2}=180.47 \\
\mathrm{df}=12, p<0.0001^{*}\end{array}$} \\
\hline African Amer & $449(4.4 \%)$ & $41(4.7 \%)$ & $55(3.4 \%)$ & $58(7.8 \%)$ & $110(7.5 \%)$ & \\
\hline Hispanic/Amer & $326(3.2 \%)$ & $30(3.4 \%)$ & $54(3.4 \%)$ & $38(5.1 \%)$ & $65(4.4 \%)$ & \\
\hline Indian/Asian & & & & & & \\
\hline Unknown & $1,919(18.7 \%)$ & $101(11.5 \%)$ & $229(14.4 \%)$ & $74(10.0 \%)$ & $111(7.6 \%)$ & \\
\hline \multicolumn{7}{|l|}{ Marital status } \\
\hline Married & $5,783(56.3 \%)$ & $568(64.9 \%)$ & $917(57.6 \%)$ & $469(63.3 \%)$ & $498(34.1 \%)$ & \multirow[t]{3}{*}{$\begin{array}{l}\text { Wald } \chi^{2}=198.82 \\
\mathrm{df}=8, p<0.0001^{*}\end{array}$} \\
\hline Never married & $974(9.5 \%)$ & $46(5.3 \%)$ & $146(9.2 \%)$ & $47(6.3 \%)$ & $166(11.4 \%)$ & \\
\hline $\begin{array}{l}\text { Divorced/separated/ } \\
\text { widowed/unknown }\end{array}$ & $3,507(34.2 \%)$ & $261(29.8 \%)$ & $529(33.2 \%)$ & $225(30.4 \%)$ & $796(54.5 \%)$ & \\
\hline Homelessness & & & & & & \multirow{3}{*}{$\begin{array}{l}\text { Wald } \chi^{2}=286.68 \\
\mathrm{df}=4, p<0.0001^{*}\end{array}$} \\
\hline Yes & $145(1.4 \%)$ & $10(1.1 \%)$ & $30(1.9 \%)$ & $7(0.9 \%)$ & $193(13.2 \%)$ & \\
\hline No & $10,119(98.6 \%)$ & $865(98.9 \%)$ & $1,562(98.1 \%)$ & $734(99.1 \%)$ & $1,267(86.8 \%)$ & \\
\hline
\end{tabular}

${ }^{*} p<0.01$.

geriatric patients with comorbid PTSD, 24.2\% $(n=212)$ actually used outpatient PTSD services over the two-year prospective evaluation period, while among geriatric patients with comorbid substance abuse, $30.7 \%(n=448)$ actually used substance abuse treatment services. Among all comorbidity groups, use of non-psychiatric outpatient services was high.

\section{Costs of care}

Table 3 demonstrates costs of care for geriatric veterans with BPD. Annual costs for veterans with comorbid PTSD, substance abuse, other anxiety dementia were higher $(\$ 15,143, \$ 19,618, \$ 13,415$, $\$ 30,157$, respectively) compared to veterans without these conditions $(\$ 13413) \quad\left(\chi^{2}=820.6, \quad \mathrm{df}=4\right.$, $p<0.0001)$. Among the four comorbidity groups, annual costs for veterans with comorbid other anxiety were nearly equal to geriatric bipolar veterans without comorbidity-at $\$ 13,415$ per patient, while annual costs for veterans with comorbid dementia were over twice as much, at $\$ 30,157\left(\chi^{2}=136.58, \mathrm{df}=3\right.$, $p<0.0001)$. Hospital costs represented a larger cost expenditure per patient in relation to other types of services. In contrast, pharmacy costs represented the smallest expenditure per patient in relation to other types of services.

\section{DISCUSSION}

Our results demonstrate that among geriatric patients with BPD, comorbid PTSD, substance abuse, other anxiety or dementia occur in nearly $29 \%$ of individuals, and that clinical characteristics, health resource use patterns and health care costs differ depending on the type of comorbidity. Findings from mixed age bipolar populations demonstrate that $36 \%$ of individuals with BPD have an additional Axis I disorder, with alcohol abuse being the most common one, followed by anxiety disorders. Comorbidity in younger populations with BPD is associated with greater functional impairment, higher health care costs and generally worse health outcomes (Kleinman et al., 2003; Tondo and Ghiani, 2003; Singh et al., 2005). The $28.6 \%$ comorbidity proportion in our older adult bipolar population likely represents a lower boundary 
Table 2. Inpatient and outpatient care over a prospective two-year period among patients with bipolar disorder age 60 and over

\begin{tabular}{|c|c|c|c|c|c|c|}
\hline \multirow[t]{2}{*}{ Type of care variable } & \multicolumn{5}{|c|}{ Psychiatric Comorbidity Group } & \multirow{2}{*}{$\begin{array}{l}\text { Test of significance } \\
\text { between comorbidity } \\
\text { groups }\end{array}$} \\
\hline & $\begin{array}{c}\text { BPD only } \\
(n=10,264)\end{array}$ & $\begin{array}{l}\text { BPD and } \\
\text { PTSD } \\
(n=875)\end{array}$ & $\begin{array}{l}\text { BPD and } \\
\text { other anxiety } \\
(n=1,592)\end{array}$ & $\begin{array}{l}\text { BPD and } \\
\text { dementia } \\
(n=741)\end{array}$ & $\begin{array}{c}\text { BPD and } \\
\text { substance abuse } \\
(n=1,460)\end{array}$ & \\
\hline $\begin{array}{l}\text { Patients with hospitalization } \\
\mathrm{N}(\%) \\
\text { Number of inpatient stays }\end{array}$ & $3181(31.0 \%)$ & $305(34.9 \%)$ & $578(36.3 \%)$ & $436(58.8 \%)$ & $837(57.3 \%)$ & \\
\hline $\begin{array}{l}\text { Mean } \pm \text { SD } \\
\text { Median } \\
\text { Number of innatient davs }\end{array}$ & $\begin{array}{c}4.5 \pm 3.9 \\
4\end{array}$ & $\begin{array}{c}4.6 \pm 3.6 \\
4\end{array}$ & $\begin{array}{c}4.8 \pm 4.6 \\
4\end{array}$ & $\begin{array}{c}5.5 \pm 4.4 \\
4\end{array}$ & $5.5 \pm 5.0$ & $\begin{array}{c}\text { Kruskall-Wallis } \chi^{2}=56.23 \\
\text { df }=4, p<0.0001^{*}\end{array}$ \\
\hline $\begin{array}{l}\text { Number of inpatient days } \\
\text { Mean } \pm \text { SD } \\
\text { Median } \\
\text { All outpatient visits }\end{array}$ & $\begin{array}{c}57.3 \pm 100.7 \\
19\end{array}$ & $\begin{array}{l}41.5 \pm 76.1 \\
16\end{array}$ & $\begin{array}{c}45.2 \pm 83.0 \\
16\end{array}$ & $\begin{array}{c}79.7 \pm 111.6 \\
35\end{array}$ & $\begin{array}{c}62.0 \pm 100.8 \\
22\end{array}$ & $\begin{array}{c}\text { Kruskall-Wallis } \chi^{2}=84.62 \\
\mathrm{df}=4, p<0.0001^{*}\end{array}$ \\
\hline $\begin{array}{l}\text { Patients with OP visits } \\
\mathrm{N}(\%)\end{array}$ & $10036(97.8 \%)$ & $870(99.4 \%)$ & $1588(99.7 \%)$ & $697(94.1 \%)$ & $1435(98.3 \%)$ & $\begin{array}{c}\text { Kruskall-Wallis } \chi^{2}=530.68, \\
\text { df }=4, p<0.0001^{*}\end{array}$ \\
\hline $\begin{array}{l}\text { Mean } \pm \text { SD } \\
\text { Median } \\
\text { Mental health care visits } \\
\text { Patients w/MH visits }\end{array}$ & $\begin{array}{c}51.4 \pm 70.9 \\
35\end{array}$ & $\begin{array}{c}84.0 \pm 92.2 \\
57\end{array}$ & $\begin{array}{l}68.0 \pm 76.1 \\
\quad 46\end{array}$ & $\begin{array}{c}57.1 \pm 100.8 \\
34\end{array}$ & $\begin{array}{c}82.1 \pm 108.9 \\
51\end{array}$ & \\
\hline $\mathrm{N}(\%)$ & $8737(85.1 \%)$ & $849(97.0 \%)$ & $1491(93.7 \%)$ & $587(79.2 \%)$ & $1351(92.5 \%)$ & $\begin{array}{c}\text { Kruskall-Wallis } \chi^{2}=472.48, \\
\text { df }=4, p<0.0001^{*}\end{array}$ \\
\hline $\begin{array}{l}\text { Mean } \pm \text { SD } \\
\text { Median }\end{array}$ & $\begin{array}{l}17.0 \pm 49.1 \\
8\end{array}$ & $\begin{array}{l}33.1 \pm 62.2 \\
14\end{array}$ & $\begin{array}{c}22.0 \pm 47.8 \\
9\end{array}$ & $\begin{array}{c}22.7 \pm 84.6 \\
7\end{array}$ & $\begin{array}{l}38.6 \pm 81.4 \\
12\end{array}$ & \\
\hline $\begin{array}{l}\text { Non-psychiatric health care } \\
\text { Patients w/Non-psych visits }\end{array}$ & & & & & & \\
\hline $\mathrm{N}(\%)$ & $9779(95.3 \%)$ & $857(97.9 \%)$ & $1572(98.7 \%)$ & $684(92.3 \%)$ & $1412(96.7 \%)$ & $\begin{array}{c}\text { Kruskall-Wallis } \chi^{2}=266.55, \\
\text { df }=4, p<0.0001^{*}\end{array}$ \\
\hline $\begin{array}{l}\text { Mean } \pm \text { SD } \\
\text { Median }\end{array}$ & $\begin{array}{c}37.6 \pm 42.7 \\
27\end{array}$ & $\begin{array}{l}52.5 \pm 51.2 \\
39\end{array}$ & $\begin{array}{c}47.8 \pm 48.5 \\
34\end{array}$ & $\begin{array}{l}38.7 \pm 45.1 \\
25.5\end{array}$ & $\begin{array}{l}46.5 \pm 52.6 \\
33\end{array}$ & \\
\hline
\end{tabular}

${ }^{*} p<0.01$.

for prevalence of these conditions. This may have been, at least in part, because individuals with triple diagnosis and other comorbidities were not included in the analysis. We also suspect the reported rates are an underestimate of true prevalence of comorbidity for the following reasons: (1) underreporting of comorbid diagnoses in patients with a serious mental disorder diagnosis; (2) limited diagnostic precision in the sample by the case registry methodology; and (3) the fact that many providers might not code subsyndromal symptoms thought to be secondary to a primary mood disorder.

Among geriatric veterans with BPD, the overall rate for anxiety disorders was $15.2 \%$-PTSD was seen in $5.4 \%$ of individuals and other anxiety disorders were seen in $9.8 \%$ of individuals. Simon and colleagues (2004) reported that comorbid anxiety disorders are common in mixed age bipolar samples, with over onehalf of patients experiencing lifetime comorbid anxiety and $30.5 \%$ experiencing current anxiety disorder. Rates of PTSD in this veteran population are within the rates of $0.9-6.4 \%$ seen in civilian bipolar samples (Simon et al., 2004). In the older bipolar sample presented here, individuals with PTSD had the highest overall use of outpatient services compared to other comorbidity groups.

Individuals with substance abuse in this elderly bipolar population are more likely to be younger, minority, unmarried and homeless compared to elderly bipolar populations with anxiety disorders or dementia. Other investigators have documented that comorbid substance abuse is associated with fewer psychosocial resources among mixed age populations of individuals with serious mental illness (Nolen et al., 2004; Folsom et al., 2005). Use of specialty substance abuse treatment was quite low in this population (about $30 \%$ of elderly individuals with BPD and substance abuse). Reasons for the low use are not clear. Because diagnoses were assigned during clinical visits by treating clinicians it is not possible to determine the acuity or severity of the comorbid conditions. While it is likely that these were conditions that received at least some treatment focus, it can not be concluded that these were active or acute treatment 
Table 3. Costs for care of patients with bipolar disorder age 60 and older by psychiatric comorbidity, FY01 ${ }^{\text {a }}$

\begin{tabular}{|c|c|c|c|c|c|c|}
\hline \multirow[t]{2}{*}{ Variable } & \multicolumn{5}{|c|}{ Psychiatric comorbidity group } & \multirow{2}{*}{$\begin{array}{c}\text { Test of significance } \\
\text { between comorbidity groups }\end{array}$} \\
\hline & $\begin{array}{c}\text { BPD only } \\
(n=10,264)\end{array}$ & $\begin{array}{l}\text { BPD and PTSD } \\
\quad(n=875)\end{array}$ & $\begin{array}{c}\text { BPD and other } \\
\text { anxiety }(n=1,592)\end{array}$ & $\begin{array}{c}\text { BPD } \\
\text { and dementia } \\
(n=741)\end{array}$ & $\begin{array}{c}\text { BPD } \\
\text { and substance } \\
\text { abuse }(n=1,460)\end{array}$ & \\
\hline $\begin{array}{l}\text { Annual costs } \\
\text { per patient }\end{array}$ & 13,413 & 15,143 & 13,415 & 30,157 & 19,618 & $\begin{array}{c}\text { Kruskall-Wallis } \chi^{2}=820.6 \\
\text { df }=4, p<0.0001^{*}\end{array}$ \\
\hline $\begin{array}{l}\text { Outpatient }{ }^{\mathrm{b}} \text { costs } \\
\text { per patient }\end{array}$ & 5,446 & 8,997 & 7,563 & 7,084 & 7,654 & $\begin{array}{c}\text { Kruskall-Wallis } \chi^{2}=626.81 \\
\text { df }=4, p<0.0001^{*}\end{array}$ \\
\hline $\begin{array}{l}\text { Hospital }{ }^{c} \text { costs } \\
\text { per patient }\end{array}$ & 21,663 & 19,339 & 15,364 & 22,980 & 18,823 & $\begin{array}{c}\text { Kruskall-Wallis } \chi^{2}=20.13 \\
\text { df }=4, p=0.0005^{*}\end{array}$ \\
\hline $\begin{array}{l}\text { Psychiatric care } \\
\text { costs per patient }\end{array}$ & 2,739 & 3,526 & 3,047 & 6,767 & 7,366 & $\begin{array}{c}\text { Kruskall-Wallis } \chi^{2}=1027.12, \\
\text { df }=4, p<0.0001^{*}\end{array}$ \\
\hline $\begin{array}{l}\text { Pharmacy costs } \\
\text { per patient }\end{array}$ & 1,436 & 2,224 & 1,852 & 1,605 & 1,450 & $\begin{array}{c}\text { Kruskall-Wallis } \chi^{2}=295.80 \\
\text { df }=4, p<0.0001^{*}\end{array}$ \\
\hline
\end{tabular}

${ }^{\mathrm{a}}$ All costs in US dollars.

${ }^{\mathrm{b}}$ Includes medical and psychiatric visits for individuals that had outpatient care.

cIncludes medical and psychiatric admissions for individuals that had inpatient care.

${ }^{*} p<0.01$.

problems and this could also account for the low use of substance abuse and PTSD services. Alternatively, it is possible that individuals with dual diagnoses may have more difficulty accessing substance abuse services. Verduin et al. (2005) recently noted that in a mixed age VA sample, patients with comorbid bipolar and substance use disorders were significantly less likely than those with substance use disorder alone to be referred for intensive substance abuse treatment. In an elderly population, presence of medical disease may both make access to outpatient specialty more difficult (e.g. reduced ability to drive to appointments), and yet at the same time more essential (ongoing substance abuse is likely to greatly complicate the management of medical illness such as diabetes or cardiovascular disease).

Dementia was present in $4.5 \%$ of geriatric veterans with BPD. Bipolar patients with dementia were significantly older than groups with other types of comorbidity, and had the most extensive use of inpatient services. Overall costs of annual care were over twice that of elderly veterans with BPD without comorbidity. Unfortunately, this case registry format did not permit an evaluation of type of dementia and whether dementia was related to etiology of BPD (e.g. secondary mania). It is not clear if these were individuals who had long-standing BPD who eventually became demented or if these were individuals who developed BPD as a result of new-onset neurological pathology/illness. Gildengers and colleagues (2004) recently reported that a significant proportion of older bipolar patient exhibit neuropsychological deficits, and Kessing (2004) noted that the risk of dementia seems to increase with the number of episodes in individuals with BPD. The clinical implications of these findings are especially important for geriatric bipolar patients with additional comorbidity - if comorbidity is untreated or under treated, e.g. comorbid substance abuse and anxiety, this is likely to lead to bipolar relapse and potentially increased rates of dementia over time.

Finally, interpretation of this analysis is limited by methodology, the treatment setting and characteristics of the patients. The case registry format may predispose to some impreciseness in diagnosis for both bipolar and comorbid diagnoses. Because this was a VA sample, the population was predominantly male, and thus comorbidity presentations might differ from a more gender-balanced population. Combatrelated PTSD would be expected to be uncommon in general bipolar populations, and combat-related vs non-combat related PTSD are known to have potentially different courses and outcomes. Finally, since cases of substance abuse and anxiety were identified from clinical settings alone, it might be expected that substance abuse and anxiety were underdetected, and true rates are actually higher than those reported here.

\section{CONCLUSIONS}

Comorbid substance abuse, anxiety or dementia are seen in at least $29 \%$ of geriatric veterans with BPD. Additional research is needed to better understand presentation of illness and modifiable factors that may influence outcomes. 


\section{ACKNOWLEDGEMENTS}

Portions of this data have been presented at the American Association of Geriatric Psychiatry (AAGP) Annual Meeting, San Diego, CA. March 4, 2005. This study was supported in part by National Institute of Mental Health (NIMH) K23 MH065599 (Dr. Sajatovic).

\section{REFERENCES}

Folsom DP, Hawthorne W, Lindamer L, et al. 2005. Prevalence and risk factors for homelessness and utilization of mental health services among 10.340 patients with serious mental illness in a large public mental health system. Am J Psychiatry 162(2): 370376.

Gildengers AG, Butters MA, Seligman K, et al. 2004. Cognitive functioning in late-life bipolar disorder. Am J Psychiatry 161(4): 736-738.

Hegel MT, Unutzer J, Tang L, et al. 2005. Impact of comorbid panic and posttraumatic stress disorder on outcomes of collaborative care for late-life depression in primary care. Am J Geriatr Psychiatric 13(1): 48-58.

Kessing LV, Anderson PK. 2004. Does the risk of developing dementia increase with the number of episodes in patients with depressive disorder and in patients with bipolar disorder? J Neurol Neurosurg Psychatry 75(12): 1662-1666.

Kleinman L, Lowin A, Flood E. 2003. Costs of BPD. Pharmacoeconom 21(9): 601-622.
Langa KM, Larson EB, Wallace RB, et al. 2004. Out-of-pocket health care expenditures among older American with dementia. Alzheimer Dis Associ Disord 18(2): 90-98.

Nolen WA, Luckenbaugh DA, Altshuler LL, et al. 2004. Correlates of 1-year prospective outcome in BPD: results from the Stanley Foundation Bipolar Network. Am J Psychiatry 61(8): 14471454.

Patterson RL, Jeste DV. 1999. The potential impact of the babyboom generation on substance abuse among elderly persons. Psychiatric Serv 50(9): 1184-1188.

Sajatovic M, Blow FD, Ignacio RV, Kales HC. 2004. Age-related modifiers of clinical presentation and health service use among veterans with BPD. Psychiatric Serv 55(9): 1014-1021.

Simon NM, Otto MW, Wisniewsk SR, et al. 2004. Anxiety disorder comorbidity in bipolar patients: data from the first 500 participants in the Systematic Treatment Enhancement Program for Bipolar Disorder (STEP-BO). Am J Psychiatry 161(12): 22222229.

Singh J, Mattoo SK, Sharan P, Basu D. 2005. Quality of life and its correlates in patients with dual diagnosis of bipolar affective disorder and substance dependence. BPDs 7: 187-191.

Tondo L, Ghiani C. 2003. Psychiatric comorbidity in BPD. BPD 5 (Suppl 1): 19.

Van Gerpen MW, Johnson JE, Winstead DK. 1999. Mania in the geriatric patient population: a review of the literature. Am J Geriatr Psychiatry 7: 188-202.

Verduin ML, Carter RE, Brady KT, Myrick H, Timmerman MA. 2005. Health service use among persons with comorbid bipolar and substance use disorders. Psychiatric Serv 56(4): $475-480$. 